\title{
LA ENSEŃANZA DEL DERECHO DESDE UNA PERSPECTIVA SOCIOLÓGICO JURÍDICA. UN ESTUDIO DE CASO EN UNA FACUlTAD DE DERECHO
}

\author{
Silvina PEZZetTa*
}

RESUMEN: Este artículo analiza los resultados de una recolección de datos, con miras a comprender el impacto del código educativo en la conciencia subjetiva de los estudiantes de la Facultad de Derecho de la Universidad Nacional de Rosario (Argentina). De esta manera, se intenta "desnaturalizar", con una base teórica sociológica, el fenómeno educativo en el cual nos vemos inmersos quienes formamos parte del mundo juridico.

Palabras ClaVE: Enseñanza del Derecho - Estudio de caso - Sociología de la Educación - Teoría General del Derecho - Código Educativo.

\section{THE TEACHING OF LAW FROM A LEGAL SOCIOLOGICAL PERSPECTIVE. A CASE STUDY IN A LAW SCHOOL}

ABSTRACT: This article explores the results of a research of students' answers based on the theory of Basil Bernstein. The goal was to study the impact of the educational code on the subjective conciousness of Law students at the Universidad Nacional de Rosario (Argentina). In this way, we attempt to denature the educational process in which we work everyday as lawyers, with a sociological theory basis.

KEY WORDS: Law Teaching - Case Study - Sociology of Education Theory of the Law - Educational Code.

SUMARIO: Introducción. I. La enseñanza del Derecho y La sociología de la Educación. 1. El código educativo o de conocimiento educacional. 2. Las modalidades del código de conocimiento educacional. 3. El dispositivo pedagógico. II. Los objetivos de la toma de datos. El estudio de las produccio-

\footnotetext{
Abogada. Doctoranda de la Facultad de Derecho de la Universidad Nacional de Rosario (Argentina), Jefa de Trabajos Prácticos de Filosofía del Derecho, becaria del CONICET. Correo electrónico: silvinapazzetta@gmail.com

Fecha de recepción: 8 de mayo de 2008 .

Fecha de aprobación: 29 de agosto de 2008.
} 
nes de los estudiantes. III. Sobre los conceptos de Derecho. IV. Características de la toma de datos. $V$. Los resultados de las producciones textuales requeridas. Primer año. VI. Resultados del grupo de estudiantes avanzados. VII. El concepto del Derecho en la resolución del caso. VIII. Análisis de los datos: La orientación hacia los significados relevantes; similitudes y discordancias aparentes en el concepto de Derecho. Clasificación fuerte. 1. Las prácticas de interacción especializadas y la pedagogía. El enmarcamiento fuerte. Diferencias entre ambos grupos. Conclusiones

\section{INTRODUCCIÓN}

El siguiente trabajo tiene por finalidad mostrar los resultados de una toma de datos intencional y preliminar, que tuvo como objetivo la búsqueda de la corroboración o refutación de la hipótesis (en sentido débil) ${ }^{1}$, de que la socialización en una institución educativa incide de manera decisiva en la formación de un tipo de conciencia subjetiva, en este caso, la manera de "ser abogado". Se trata del análisis de las respuestas y resultados a la pregunta por el concepto de Derecho y de la resolución de un caso imaginario por parte de un grupo de estudiantes de la carrera de Abogacía de la Facultad de Derecho de la Universidad Nacional de Rosario (Argentina). Los datos recabados, si bien pertenecen al período de prueba ${ }^{2}$ de los instrumentos de recolección de los mismos y, como tales, no son concluyentes, son relevantes, en razón de las coincidencias -y disidencias- entre los estudiantes de primer ańo y de los últimos ańos de la carrera.

Nuestra investigación toma como guía la sociología de la educación de Basil Bernstein, para quien esta es un proceso de transmisión simbólica; en este caso, la transmisión simbólica tiene lugar mediante la práctica pedagógica en una institución de educación formal. Intentaremos mostrar la influencia de esta a nivel subjetivo, es decir, a nivel de la conciencia jurídica de los estudiantes de Derecho de la institución seleccionada.

En cuanto a la metodología, este trabajo podría clasificarse en la modesta categoría que señala Klimovsky como explicación conceptual o pseudoexplicación. Esta es una forma de encuadrar un fenómeno o

Decimos en sentido débil, pues el trabajo es uno de los primeros ingresos al campo dentro del marco de una investigación doctoral. Tal investigación no se basa en el método hipotético deductivo, dentro del cual corresponde hablar de hipótesis a confirmar o refutar, sino que utiliza un paradigma constructivista. En este, se parte más bien de supuestos, los que son una especie de hipótesis en sentido más laxo, pero que cumplen una función orientadora de la investigación. Además, la evidencia empírica tiene un lugar de relevancia, como en el caso de la investigación basada en el paradigma positivista. ción. Rosario: Editorial Homo Sapiens, pp. 93 y ss. 
datos determinados en categorías o teorías determinadas ${ }^{3}$. Por lo demás, debemos aclarar que lo pedagógico y el discurso jurídico son objetos a describir en este trabajo. No obstante, se pone de relieve la pertinencia jurídica del mismo cuando acordamos en que el Derecho, como objeto, es una construcción social y, por tanto, es de sumo interés estudiar uno de los procesos en que se origina, esto es, en la formación de los futuros abogados.

\section{La enseńanza Del DeRecho Y LA SOCIOlogía DE LA EDUCACIÓN}

Desde sus comienzos, la sociología de la educación tiene por meta principal el estudio del proceso de socialización que se produce en las instituciones de educación formal. Nuestro trabajo sigue esta línea y gira en torno a la enseñanza del Derecho en la Facultad de Derecho de la U.N.R. En esta oportunidad hemos seleccionado el estudio de un caso como una estrategia metodológica que permite ahondar con profundidad un fenómeno como el que nos interesa ${ }^{4}$. En este sentido, es importante remarcar que, cuando se estudia la enseńanza del Derecho desde una perspectiva sociológica, estamos ingresando a la sociología del Derecho. Esto en razón de que el objeto de la disciplina mencionada es el Derecho y sus diversas formas de producción y aplicación. Consideramos que una de las maneras en que el Derecho se produce es a través de su enseñanza, mirada novedosa si se quiere, para quienes estamos más acostumbrados a pensar las fuentes del Derecho según la dogmática más tradicional.

La reflexión en torno a la enseñanza del Derecho es un quehacer que preocupa desde hace ańos a quienes estamos involucrados en el mundo jurídico. En Argentina, los estudios sobre el tema suelen ser abordados desde la pedagogía o desde un discurso prescriptivo con más o menos fundamentos en teorías. Sin embargo, creemos necesario enfocar la educación jurídica desde la perspectiva de la sociología de la Educación, que permite un análisis más rico e intenso de lo que ocurre en las Facultades de Derecho.

La sociología de la Educación, por ser sociología, tiene por intención principal "desnaturalizar" lo que sucede en el plano social, y por esto mismo nos interesa. Por lo demás, aunque el lenguaje de tal teoría no es manejado cotidianamente por nosotros, la perspectiva teórica adoptada será explicitada de la manera más clara posible a fin de alcanzar los objetivos

\footnotetext{
3 Kurmovsky, Gregorio e Hidalgo, Cecilia (2001). La inexplicable sociedad. Cuestiones de epistemología de las ciencias sociales, $3^{\mathrm{a}}$ ed. Buenos Aires: AZ, pp. 64 y ss.

4 Pérez Serrano, Gloria (1998). Investigación cualitativa. Retos e interrogantes. Madrid: La Muralla.
} 
propuestos. Solicitamos, por tal razón, la paciencia del lector para con los aspectos teóricos desarrollados antes de exponer los resultados empíricos.

En la línea de trabajo propuesta, y tal como adelantamos, nos ha interesado especialmente la propuesta teórica de Basil Bernstein, quien fuera un sociólogo británico especializado en el área de la sociología de la Educación. Su teoría de la educación no es pedagógica, sino sociológica. Entiende por eso que la educación es una forma de transmisión simbólica y que, en cada práctica pedagógica estamos en presencia de un dispositivo transmisor: un transmisor cultural, que sirve tanto para la reproducción como para la producción de la cultura.

Explicitaremos algunos de los conceptos básicos de este autor, que son los que permitieron la realización de la toma de datos y su posterior análisis. Así, veremos los conceptos de código educativo y discurso pedagógico, y sus respectivos deslindes analíticos.

\section{El código educativo o de conocimiento educacional}

Desde la perspectiva de Bernstein el código educativo comprende tres sistemas de mensajes: el curriculum, la pedagogía y la evaluación. Es necesario aclarar qué entiende por código, para luego poder comprender que, de este concepto más general, obtiene el de código educativo. El código es un principio regulador (de las experiencias del sujeto) que se adquiere tácita e informalmente; no se puede enseñar un código a nadie. Los códigos son aprendidos más que enseñados. Se adquieren códigos del mismo modo que se adquiere el código lingüístico, el código gramatical. ... ${ }^{5}$ Cuando el sujeto adquiere o aprende el código, está en condiciones de producir lo que vale como conducta socialmente aceptable. Este determina lo que uno piensa, el modo de ser y cómo se ocupa el lugar en el que se está. Actúan como principios de selección y combinación. Adquirido el código, se adquieren las reglas de reconocimiento y las reglas de adquisición. Por medio del manejo de estas, el sujeto está en condiciones de seleccionar los significados relevantes en un contexto determinado y llevar adelante conductas aceptables.

Retomando el concepto de código educativo, podemos distinguir a nivel analítico los tres mensajes que componen el código educativo, es decir, el código que aprende un sujeto en una institución de enseńanza formal: el currículum, la pedagogia y la evaluación. Bernstein recorta así al currículum: definiré al currículum en términos del principio por el cual ciertos periodos de tiempo y sus contenidos son puestos en una relación especial unos con otros ${ }^{6}$. En otras palabras, los elementos aquí son: tiempo y y la formación de la conciencia jurídica. Córdoba: Sima, p. 6.

6 Brígido, Ana María (2006). Sociología de la educación: temas y perspectivas fundamentales. Córdoba: Ed. Brujas, p. 253. 
contenidos. En un determinado tiempo se debe desarrollar el contenido seleccionado.

En cuanto a la pedagogía, esta es la forma en que se reproduce y produce la cultura. Aquí también hay reglas: de jerarquía, de secuencia y ritmo $y$ de criterio. En todo proceso de transmisión simbólica, en todo proceso educativo, existe una pedagogía y estas reglas. Lo que puede variar es la manera en que se presentan.

Por último, la evaluación condensa los otros dos mensajes y es la manera en que se valida el conocimiento adquirido.

En particular, nos interesa aquí el concepto de código educativo, el currículum y sus clases, sobre las que ampliaremos en su oportunidad, y la pedagogía.

\section{Las modalidades del código de conocimiento educacional}

Bernstein distingue entre dos tipos de códigos educativos surgidos de acuerdo a los valores que asuman la clasificación expresada en el curriculum, la pedagogía (expresiva del control a través del enmarcamiento y sus reglas), la evaluación, la organización de la institución -nivel macroinstitucional- $y$, a nivel macroestructural, las características del orden social.

La primera modalidad es el código de colección. Este implica un currículum de colección, con una organización en compartimentos estancos de las materias, una estratificación del conocimiento, un estatus del profesor que viene transmitido por la asignatura que dicta y una fuerte separación del conocimiento educativo del conocimiento común. La pedagogía en este tipo de códigos se basa en relaciones jerárquicas, ritualizadas, de carácter visible. Se trata de relaciones interpersonales que se desarrollan en un enmarcamiento fuerte, se sabe así quien ocupa cada rol, quien tiene el control de la situación. El enmarcamiento es fuerte y se aprende en profundidad. La evaluación es de resultado y no de procesos.

Por el contrario, los códigos integrados contienen un currículum integrado, es decir, con límites difusos, sin estratificación del conocimiento ni diferencias entre los docentes. La separación entre conocimiento educativo y de sentido común no es clara. En suma, estamos frente a una clasificación débil. La organización de las relaciones pedagógicas es flexible, se negocia la selección, el ritmo y la secuencia. Es decir, el enmarcamiento es débil. La evaluación es de procesos y no de resultados.

\section{El dispositivo pedagógico}

Durante los últimos ańos de su trabajo, Bernstein se ocupó de diseñar una teoría que proveyera los conceptos básicos para entender lo que sucede en cada comunicación pedagógica. Supuso que, sin importar el contenido o el nivel de educación referido, ante cada práctica pedagógica 
nos encontramios con lo que llamó el dispositivo pedagógico. Este es el que ... regula fundamentalmente la comunicación que hace posible, de esta forma actúa selectivamente en el significado potencial. El dispositivo regula continuamente el universo ideal de significados pedagógicos potenciales de manera tal que restringe o mejora sus realizaciones? ${ }^{7}$. Para decirlo de manera simple, la comunicación que tiene lugar en un aula puede ser entendida como una comunicación que se da por medio del dispositivo pedagógico, que regula qué se puede decir, cómo se puede decir, y como será evaluado lo antedicho. Por eso, ahora veremos que el dispositivo es un conjunto de tres tipos de reglas.

Por una parte, encontramos las reglas de distribución, que son las más importantes; por la otra, las de recontextualización y evaluación. Las reglas de distribución son las que determinan qué va a ser comunicado, enseńado. Son las que determinan lo pensable, lo que es posible de ser enseńado. Por eso, estas reglas son más importantes que las otras: determinan a las otras. Y, además, dan lugar en lo sociológico, a la construcción de un campo de producción del conocimiento.

Luego, tenemos a las reglas de recontextualización. Estas son las que permiten apropiarse de lo generado en el campo de producción a que dieron lugar las reglas de distribución y se traducen en el discurso pedagógico. Este discurso no es más que la forma de apropiación de un discurso instruccional (contenido) sometido a un discurso regulativo (reglas de carácter moral ajenas al campo de producción de conocimiento). En este caso, a nivel sociológico encontramos un campo de recontextualización. La Facultad, por motivos que luego veremos, pertenece mayormente a este campo.

Por último, las reglas de evaluación son las que condensan el significado de todo dispositivo. Ya que el dispositivo es el que provee la forma "correcta" de conciencia, la evaluación adquiere su carácter fundamental.

\section{LOS OBJETIVOS DE LA TOMA DE DATOS. EL ESTUdIO DE LAS PRO- DUCCIONES DE LOS ESTUDIANTES}

Hemos hablado del código educativo como un conjunto de tres sistemas de mensajes: el currículum, la pedagogía y la evaluación. Conviene ahora señalar que estos conceptos son traducidos a nivel subjetivo, es decir, de manera tal que puedan verse reflejados en las producciones y acciones de los estudiantes. En esta toma de datos nos ha interesado lo que producen los alumnos de la carrera de abogacía, y por eso es necesario mostrar los conceptos que implica el código educativo a nivel de la conciencia subjetiva.

Bernstein, Basil (1996) Pedagogy, Symbolic Control and Identity. Exeter: Taylor \& Francis, p. 41. 
A fin de poder observar los criterios de la recolección de los datos y analizarlos, diremos lo siguiente: el código educativo, a nivel subjetivo, se transforma en lo que Bernstein denomina: orientación a los significados, prácticas de interacción especializadas y producciones textuales. En este trabajo estamos en condiciones de visualizar los tres conceptos. En primer lugar, se ha requerido una producción textual determinada. En segundo lugar, se pudo observar, mientras la realizaban, las prácticas de interacción. Por último, el análisis de los resultados revela cuál es la orientación hacia los significados. Estos últimos son los que esperábamos, de acuerdo a la hipótesis de la que partimos, aunque con algunas sorpresas. En este orden de ideas, se esperaba encontrar claras diferencias entre los estudiantes de primer año y los del último tramo de la carrera. Y esto por la influencia que tiene la socialización en un código, de acuerdo a la teoría de Bernstein.

Partimos del presupuesto de que en la Facultad de Derecho rige un código educativo de colección. Y que el discurso pedagógico recontextuali$z a$, predominantemente, algunos tipos del positivismo jurídico ${ }^{8}$. Antes de avanzar sobre los detalles de la toma de datos y su análisis, incluiremos un apartado en el que se detallarán los diferentes conceptos de Derecho sobre los que luego hemos hecho las clasificaciones.

\section{SOBRE LOS CONCEPTOS DE DERECHO}

Para poder fundamentar las categorías diseñadas, necesitamos explicitar los criterios seguidos. Para ello, seguiremos algunas precisiones sobre la discusión positivismo-jusnaturalismo de Carlos Nino?

Sobre el jusnaturalismo dice que es posible definirla como aquella postura filosófica que sostiene conjuntamente estas dos tesis:

a. Que existe un conjunto de principios morales y de justicia accesibles por medio de la razón.

b. Que no puede adjudicársele el carácter de jurídico a una norma o sistema normativo que no cumpla con los principios descriptos en la primera tesis.

8 Una tarea similar, que ha servido de base a esta, ha sido realizada en otra agencia educativa de nuestro país, la Facultad de Derecho de la Universidad Nacional de Córdoba, con resultados similares. Por lo tanto, aunque con una muestra menos representativa y con diferencias en cuanto a la forma de recolección de los datos, se ha tratado de volver a repetir la experiencia de los investigadores cordobeses. Lista, Carlos y Begala, Silvana (2003) "La presencia del mensaje educativo en la conciencia de los estudiantes: resultados de la socialización en un modelo jurídico dominante". Revista Academia, № 2, Buenos Aires, pp. 147 y ss.

9 Nino, Carlos (2005) Introducción al análisis del Derecho, 2a Ed. ampliada y revisada, 13a reimpresión. Buenos Aires: Astrea, pp. 18 y ss. 
Más complicado le resulta definir qué sea el positivismo. Aunque suele asociarse al positivismo el escepticismo ético, seńala que esto no es definitorio de tal postura. Bentham, por citar un ejemplo, es positivista y, no obstante, sostiene la posibilidad de discutir racionalmente sobre ética.

Tampoco le parece que sea necesario adherir a cierta idea de que el Derecho esté compuesto exclusiva o predominantemente por preceptos legislativos (Derecho de origen estatal), y no, por ejemplo, por normas consuetudinarias o jurisprudenciales. Caracterizando además al sistema jurídico como siempre completo, consistente, preciso. Se suele denominar tal concepción "formalismo jurídico" y está asociada a la dogmática jurídica como ciencia del Derecho. Pero esto no es tampoco lo que caracteriza al positivismo según Nino.

Una tesis que comúnmente se atribuye a los positivistas es la de que hay que cumplir con las normas jurídicas cualquiera sea su contenido. Esto es lo que tanto Nino como Bobbio coinciden en llamar "positivismo ideológico". En realidad, es perfectamente coherente sostener que el Derecho es un conjunto de normas, sin hacer referencias ni sostener que existen principios morales o éticos que obligan a dejar de lado el Derecho en determinadas circunstancias. Sostener lo contrario, es decir, que la ley por ser tal debe ser siempre obedecida es más bien una teoría de la justicia.

Llegados a este punto, en que se aclaran diversas confusiones frecuentes en la conceptualización del positivismo, Nino pone de relieve lo que caracteriza a positivistas como Ross, Hart, Bentham y Austin: definir al Derecho descriptivamente, esto es, sin hacer referencias a valoraciones. Esto permite dos cosas: hacer ciencia y una mayor eficacia en la comunicación entre juristas. Además, el hecho de describir el Derecho permite no atribuirle determinadas características que el ordenamiento jurídico no posee y que típicamente le atribuye la dogmática: completitud, coherencia, racionalidad, falta de ambigüedad, entre otras cosas. A este tipo de positivismo, que es según su análisis el que caracteriza a los autores positivistas, lo denomina "conceptual".

Observando con detenimiento el plan de estudios y los programas de las materias que se dictan en la carrera de Abogacía de la Facultad Derecho de la U.N.R. (currículum) y comparándolos con las definiciones de positivismo, podemos hacer un juicio provisorio. El discurso pedagógico recontextualiza mayoritariamente las posiciones de un discurso instruccional jurídico formalista, el positivista teórico e ideológico. Pero lo que sin dudas existe es una visión formalista de la ciencia jurídica, la ciencia dogmática del Derecho, que es la que va asociada al formalismo jurídico.

Para Nino Esta modalidad de ciencia juridica se caracteriza por ciertas actitudes ideológicas e ideales racionales respecto del derecho positivo, por determinadas funciones que cumple en relación a él y por ciertas técnicas de justificación de las soluciones que propone... En realidad, como lo han sugerido Ross y Carrió, la dogmática jurídica vigente está fuertemente impregnada de 
la ideología que analizamos en el primer capitulo, llamada por Ross "seudopositivismo" y por Bobbio, "positivismo ideológico", que consiste en reconocer la fuerza obligatoria a todo derecho positivo por el solo hecho de existir, o de ser tal. Esta ideología que, como vimos, constituye una especie de jusnaturalismo conservador a pesar del rótulo de "positivista" que frecuentemente se le ha asignado, se expresa en el lema Gesetz ist Gesetz ("la ley es la ley"), cuyo significado es que la ley positiva debe ser obedecida y aplicada por los jueces independientemente de cualquier disenso axiológico respecto de ella, el cual, en todo caso, habrá de orientarse a proponer su reforma por medios legales ${ }^{10}$.

Sobre las implicancias de estos puntos de vista en la interpretación y aplicación del Derecho, seguiremos las consideraciones de Elías Díaz. Esto será especialmente útil a la hora de analizar las resoluciones de los casos por parte de los cursantes de Filosofía del Derecho.

Nos dice el español: Cabría diferenciar a lo largo de toda la historia del Derecho y del pensamiento jurídico, claramente sobre todo desde Roma, dos tipos fundamentales de aproximación metodológica al tema de la investigación-interpretación y aplicación-realización del Derecho: uno, en el que predomina el análisis interno de la norma, investigación preferentemente lógico-formal, buscando deducir desde esa norma de carácter general, la conclusión aplicable al caso concreto; otro, en el que predomina una perspectiva en cierto modo exterior a la norma: aquella de los intereses, fines y valores a cuyo cumplimiento se orienta un determinado sistema juridico ${ }^{11}$. Estas diferencias, señala, se han marcado durante la disputa que tuvo lugar a fines del siglo XIX y durante el XX entre formalistas y conceptualistas y finalistas y realistas.

Una vez que aclaramos los puntos de vista desde los cuales vamos a categorizar y analizar los datos, estamos en condiciones de pasar a referirnos a estos.

\section{CaRaCterísticas de la toma de datos}

Se tomaron dos grupos de alumnos, en una muestra intencional, para poder cumplir con los objetivos planteados. Así, se recabaron datos en dos comisiones seleccionadas según el tiempo de permanencia de los estudiantes en la carrera. Por un lado, se trabajó con un grupo de estudiantes que estaban cursando el primer año o Ciclo Básico. Por el otro, se generaron datos a partir de un grupo de estudiantes que ya habían aprobado, como mínimo, las dos terceras partes de la carrera, que son quienes

\footnotetext{
$10 \quad$ Nino (2005) 326.

11 Díaz, Elías (1992) Sociología y Filosofia del Derecho, 1ª Ed., reimp. Madrid: Taurus, pp, 106 y ss.
} 
forman parte de la muestra tomada en un curso de Filosofía del Derecho -Ciclo Superior- ${ }^{12}$.

Los datos correspondientes a una muestra de 50 estudiantes de primer ańo, fueron recolectados el día 5 de julio del año 2007, en una clase general (que reúne a todas las comisiones de la cátedra) de Introducción al Derecho, a cargo del profesor Ciuro Caldani.

El tiempo de cursado que transitaron los estudiantes de este grupo fue muy corto. Durante todo el mes de febrero y la primera quincena de marzo, realizaron el Curso Introductorio y debieron aprobar la evaluación a fin de alcanzar la condición de alumnos regulares. Estos estudiantes han pasado un mes y medio recibiendo clases que se dividieron en tres módulos: General, cuyo objetivo es prepararlos en comprensión y análisis de textos, Derecho Privado y Derecho Público, en el que estudian los contenidos de las materias que componen esas ramas. La evaluación es sobre los contenidos de los tres módulos, y, aunque no es eliminatoria, quienes no la aprueban no pueden cursar en condición de regulares el primer año. Por lo tanto, los estudiantes que componen la muestra, en su gran mayoría $^{13}$, son aquellos que pasaron exitosamente la instancia evaluadora.

Luego del curso de ingreso, y recién el 30 de abril de 2007, comenzaron las clases de las cinco materias que componen el primer ańo (Derecho Civil I, Introducción al Derecho, Introducción a la Filosofia, Historia del Derecho e Historia Constitucional Argentina). Por lo tanto, al momento de contestar las preguntas, solo transitaron en la Facultad un período de 3 meses y medio aproximadamente.

Acerca de la forma en que se solicitó a los estudiantes que participaran por medio de la contestación de las preguntas, debemos decir que el docente a cargo del dictado de la clase es un compańero de la cátedra en la que trabajamos. El docente me presentó como becaria del CONICET ${ }^{14}$,

La Facultad de Derecho tiene un plan de estudios que ha sido reformado a finales del año 2007. Este trabajo toma el plan de estudios tal como rigiera hasta esta última reforma. El mismo constaba de un Ciclo Básico compuesto de cinco materias y un Ciclo Superior. Este no se encuentra dividido en años sino que es débilmente flexible, los estudiantes van cursando o rindiendo en calidad de alumnos libres las materias según las correlatividades establecidas. Hay una clasificación de materias por ramas: derecho privado, derecho público y materias que pueden considerarse dispersas. Para acceder al plan de estudios se puede ingresar a la página de la Facultad de Derecho de la U.N.R.: http://www.fder.unr.edu.ar/upload/ html/59.html. La mayoría de las materias es dictada por diferentes cátedras. Los contenidos son impuestos libremente por cada una de ellas. No hay un lineamiento general dado por las autoridades (compuestas por un cogobierno de cuatro claustros - docentes, estudiantes, graduados, no docentes). Estas solo aprueban el plan de estudios y los programas propuestos, pero es excepcional que alteren lo que sugieren los titulares.

Porque quienes no aprueban la evaluación pueden volver a cursar y rendir. Si aprueban, pueden cursar. Son pocos los estudiantes que lo intentan, la mayoría de los reprobados intenta rendir en condición de libres las materias que componen el primer año.

Consejo Nacional de Investigaciones Científicas y Técnicas de la República Argentina. 
aunque empleó la palabra "doctora"15, y explicó brevemente qué hacíamos quienes investigamos en Derecho. Luego, pasé a explicarles en qué consistía mi trabajo y qué era lo que necesitaba que hicieran. A tal fin, dejé claro que no había respuestas correctas o incorrectas, que la encuesta era anónima, que esto no tenía fines evaluativos ni influía en la nota para la materia Introducción al Derecho, que no debían invocar necesariamente una teoría en la respuesta y que, en lo posible, contestaran de forma espontánea. Todo lo cual, por lo demás, estaba escrito en el encabezado del pequeño cuestionario. Deliberadamente, fui vestida de una manera muy informal con la finalidad de que no me identificaran con el típico perfil del abogado litigante o funcionario judicial. Para eso me presenté utilizando un pantalón de jean, algo altamente inusual en la vestimenta de los profesores de la Facultad. Todas estas precauciones fueron tomadas a fin de que la actividad se desarrollara en un enmarcamiento ${ }^{16}$ débil, es decir, a fin de que no tomaran la instancia como una forma de evaluación o como una típica actividad académica.

Se les hizo 2 preguntas: la primera, sobre qué consideraban que es el Derecho. La segunda, si la respuesta que daban coincidía con lo que pensaban sobre este antes de ingresar a la carrera. No abordaremos los resultados de estas respuestas aquí.

Los alumnos se mostraron relativamente entusiasmados en participar, e incluso contestaban en grupo el cuestionario. Emplearon alrededor de 20 minutos para contestar las preguntas. No hubo nadie que preguntara acerca de la actividad que se proponía, ni que expusiera críticas o dudas sobre la misma.

En el caso de los estudiantes de Ciclo Superior, solicitamos a los estudiantes de la materia que dictamos que contestaran 3 preguntas. Se hizo esto el día 9 de noviembre de 2007, sobre el final del dictado de la materia y durante el horario de clases, previo al dictado de la misma por una colega de la cátedra. Los estudiantes tenían conocimiento del rol de docente que desempeño y en ocasión de la presentación de las consignas se enteraron del papel de doctoranda en función del cual se les solicitaba la colaboración. Se hicieron las mismas aclaraciones que con el grupo anterior, a fin de lograr también aquí un enmarcamiento débil.

15 El empleo de este término es corriente y sirve para marcar la diferencia entre "letrados" y "legos". Los estudiantes se dirigen a cualquier abogado, por más joven que sea, con este término si es que dicta alguna materia. Este es un indicador de la presencia de un código de colección, poniendo de manifiesto la fuerte separación entre el saber educativo y el saber corriente.

16 El enmarcamiento en la teoría de Bernstein significa saber quién pone las reglas de control de la comunicación, lo que debe ser aprendido para poder operar dentro de este. Lo mismo que con el código, las reglas del enmarcamiento no se explicitan, hay que deducirlas. Quien lo hace correctamente puede producir el texto adecuado porque domina la regla de realización. 
Contrariamente a la actitud de los estudiantes de primer ańo, no hubo ningún entusiasmo por participar. Lo que es más, a pesar de haber aclarado que nada tenía que ver la actividad con el dictado de la materia, que no era evaluativa, reinó un clima sombrío. El cuestionario fue contestado en absoluto silencio y el clima fue similar al de un examen. Tanto así que, estudiantes que llegaron tarde a la clase, al encontrarse con tal escenario, creyeron que se trataba de un examen "sorpresa". Solo un estudiante consultó con otra, a pesar de que se señaló que se podía hacer con el método de trabajo que mejor les pareciera. Algunos esbozaron quejas por lo que consideraron falta de datos para resolver el caso, pero esto no quedó reflejado en las respuestas, a pesar de que se pidió que aclararan esto en sus respuestas. Se empleó alrededor de media hora en la confección de las respuestas.

Además de preguntarles qué era para ellos el Derecho y si este concepto había cambiado en relación al que mantenían cuando ingresaron -que dejaremos de lado en el presente-, se les solicitó que resolvieran un pequeńo caso imaginario ${ }^{17}$. La finalidad del requerimiento fue observar si el concepto de Derecho ofrecido se mantiene a la hora de resolver el caso.

El caso propuesto, que debían resolver en el rol de hipotéticos jueces, fue elaborado especialmente, inspirándonos a su vez en el caso imaginario que plantea Carlos Nino en su libro Introducción al Análisis del Derecho ${ }^{18}$ a fin de graficar la diferencia entre iusnaturalismo, positivismo y positivismo conceptual.

\section{LOS RESULTADOS DE LAS PRODUCCIONES TEXTUALES REQUERIDAS. PRIMER AÑo}

De los 50 estudiantes que respondieron, 24 (48\%) contestaron a la primera pregunta utilizando en la definición términos que denotan una idea del Derecho aproximada a la del positivismo jurídico teórico o formal y también al positivismo conceptual. No podemos decir que sean positivistas ideológicos, puesto que el cuestionario no tenía tal alcance.

En todos ellos se hacía uso de palabras como normas, normas jurídicas, reglas, principios, normas emanadas por autoridad competente, obligatoriedad, sanción, vigencia en espacio y tiempo determinado, Estado y autoridad competente. Estas palabras, que construían una definición casi "escolar", y muchas veces tautológicas, del Derecho, se repiten con gran uniformidad y encabezan la definición. A estas respuestas les vamos las agruparemos bajo la letra P:

Nos pareció que en el caso de los estudiantes del Ciclo Básico no iba a haber posibilidades de resolver un caso de las mismas características, del mismo nivel de complejidad. Por tanto, la comparación no era posible y no se planteó tal resolución. 
El derecho es un conjunto de normas jurídicas que rigen en un lugar y tiempo determinado.

Es un conjunto de normas jurídicas, sancionadas por el Estado, vigentes en un momento determinado.

El Derecho son las normas impuestas por el Estado en un momento y en un lugar determinados.

Son leyes vigentes que rigen en un momento determinado, son impuestas en la sociedad.

Es un conjunto de normas obviamente vigente destinadas a regular la vida en sociedad. Impuestas por el Estado para el cumplimiento de los habitantes de esta.

El derecho es un conjunto de normas jurídicas que rigen en un lugar y tiempo determinado. Este término consta de un dos connotaciones: Derecho objetivo: Derecho como norma. Derecho subjetivo: Derecho como facultad.

En segundo lugar, vemos al grupo V (15 respuestas, 30\%) en que se conceptualiza al Derecho como normas conformes a la justicia. Claramente, encontramos una ligazón definitoria entre Derecho y norma, lo que nos indica la presencia de conceptos jusnaturalistas según la definición empleada aquí. Es remarcable el uso casi unánime de la expresión: normas conforme a la justicia. Por ejemplo:

El derecho es el conjunto de normas sociales que emanan de autoridad competente que están vigentes en un tiempo y lugar determinados, conforme a la idea de justicia.

Es el conjunto de normas dictadas por la autoridad competente, que rige en un lugar y tiempo determinados. El derecho son normas que regulan el comportamiento humano conforme a la justicia y con carácter obligatorio.

El derecho es el conjunto de normas jurídicas obligatorias que regulan la conducta humana y se elabora conforme a la justicia.

En tercer lugar, tenemos al grupo $\mathrm{H}$, que se caracteriza por el señalamiento del carácter de herramienta o instrumento positivo que asigna al Derecho (5 respuestas, 10\%). En este caso, más que contestar a la pregunta sobre lo que el Derecho es, refirieron a su función.

A continuación, encontramos un pequeño grupo de estudiantes que consideran al Derecho como una ciencia. Este grupo, que designaremos como C, está compuesto de solo 3 respuestas $(6 \%)$. 
Por último, un grupo de respuestas ha resultado inclasificable de acuerdo a las consideraciones que tomamos. Se trata de 3 respuestas, lo que constituye un $6 \%$ del total.

\section{RESULTADOS DEL GRUPO DE ESTUDIANTES AVANZADOS}

Con respecto a la muestra compuesta por 27 estudiantes que cursan Filosofía del Derecho, la clasificación es más compleja ya que se trata de estudiantes que han cursado más de las $2 / 3$ partes de la carrera y manejan un número mayor de conceptos, adquiridos durante el cursado de materias disímiles en contenidos y orientación. Aún más, como al momento de la recolección de los datos cursaban una materia en la que vieron diferentes conceptos de Derecho y que tiene como objetivo poner en crisis los conceptos que manejan, a la clasificación anterior se le ha debido agregar categorías. Estas surgen de respuestas en las que se hace uso expreso de teorías del Derecho o bien de respuestas en las que se critica la función del Derecho. Por lo demás, debemos destacar que no hay respuestas que puedan ser comprendidas en el grupo $V$, es decir, no hay concepciones jusnaturalistas del Derecho en las definiciones brindadas -aunque sí veremos jusnaturalismo en las resoluciones del caso-.

En primer lugar aparece el grupo $\mathrm{P}$ de respuestas positivistas (12 respuestas, 44,44\%). En estas hay menor uniformidad que en las respuestas positivistas de primer año. Pero, tampoco, son tan precisas y claras como muchas de aquellas:

El derecho es el conjunto de normas dictadas por un Estado de Derecho y por un gobierno constitucional en el que se regula casi todos los actos de la vida humana, desde el nacimiento, la familia, la muerte y demás actos que incumben a la vida humana, tanto en lo que es lícito (asociarse, trabajar, ejercer industria, el agro, etc.) hasta lo ilícito (delitos, faltas), tornando asi el derecho un medio para reglar y tender a la paz social como a la felicidad misma.

El Derecho es el conjunto de derechos y obligaciones que tienen los particulares. Derecho que tienen frente a otro particular y el Estado y obligaciones frente a los mismos, que deben ser respetados.

Es lo que regula las relaciones sociales, mediante normas que en caso de ser violadas traen aparejadas una determinada sanción.

En segundo lugar aparecen aquellas en que se hace hincapié en el carácter instrumental positivo -en el sentido de no crítico- del Derecho (7 respuestas, 25,92\%), grupo $\mathrm{H}$. Algunas de estas respuestas ilustran la categoría: 
Veo el derecho como un instrumento por el cual, y recurriendo a una idea primaria, se trata de componer intereses contrapuestos de los miembros de la sociedad, buscando la justicia, aunque esto último es relativo. Es un elemento que impide o trata de impedir la utilización de la fuerza privada.

Es un instrumento regulador de conductas, contenedor no solo de normas sino también de principios, doctrina y jurisprudencia. El derecho es el reflejo de una politica dada que encubre intereses particulares según la escala de valores que se quiere proteger.

En tercer lugar, con la misma cantidad de respuestas (2, 7,40\%), hay tres grupos distintos: el grupo C, compuesto de aquellas respuestas en las que se asimila Derecho a la ciencia que la estudia, el grupo $\mathrm{T}$, respuestas en las que se incluyen elementos de la teoría trialista ${ }^{19}$ para definir, el grupo TD, que emplea otras teorías del Derecho en su definición y el grupo I -respuestas inclasificables-. Por último, y por ser la única respuesta $(3,70 \%)$ que explícitamente sostiene una postura crítica del Derecho, tenemos al grupo D, cuya respuesta es la siguiente:

Uh, es un conjunto de normas que tienden a lograr una convivencia pacífica entre todos los individuos, agrupaciones, Estados. Aunque, también es una herramienta de dominación, todo, ya que refleja la ideología dominante $y$ los intereses de corporaciones y organismos internacionales ${ }^{20}$.

\section{EL CONCEPTO DEL DERECHO EN LA RESOLUCIÓN DEL CASO}

A continuación, incorporamos el texto del caso, a fin de una mayor comprensión de las finalidades propuestas y el análisis al que se arriba:

Suponga que Ud. es juez de la Corte Penal Internacional y debe fallar en el siguiente caso: El gobierno del Estado A, constitucionalmente elegido, reformó su Constitución, y reguló la declaración del estado de sitio, facultad del Presidente, por tiempo indeterminado y la aplicación de la pena de muerte en los casos en que "se atentara contra el orden público que el estado de sitio está llamado a proteger, lo que determinará en un juicio sumario el mismo poder ejecutivo que estará facultado para aplicar la pena de muerte a quienes lo violaran". Bajo el amparo de tal legislación, se enjuició y ejecutó a 20 personas que, en diferentes actos, violaron el estado de sitio mediante la circulación

19 Teoría que sigue la cátedra de Filosofía del Derecho, cuyo titular es también el Dr. Ciuro Caldani.

20. Las respuestas son transcriptas sin modificaciones, de allí las faltas de ortografía y las carencias de redacción. 
en la vía pública con pancartas opositoras al gobierno. Por tales hechos el ex presidente del Estado es acusado de homicidio. La defensa del ex presidente del Estado A sostiene que el imputado no debe ser condenado porque los hechos estaban permitidos de acuerdo a la legislación vigente y, por lo tanto, no eran delito al momento de su realización. En suma, de condenarlo se violaría el principio de nullum crimen nullum poena sine lege del derecho penal. Este principio, alega, ha sido reconocido por nuestra Constitución Nacional y por las otras constituciones de los paises de los jueces que integran el tribunal con Ud. y por la misma Corte Penal Internacional; con esto el abogado defensor señala que se caería en una contradicción jurídica insalvable. ¿Cómo fallaría Ud.? ¿Lo condenaria? ¿Lo absolvería por la razón alegada por el abogado del ex presidente?

En cuanto a la resolución del caso, aparecen aquí respuestas interesantes que develan que el positivismo ideológico es importante en la Facultad. A su vez, aparecen respuestas iusnaturalistas que no aparecieron en la contestación a la primera respuesta, aunque son pocas.

Todos, menos 2 estudiantes, condenarían al imputado. Aquí también conviene clasificar las respuestas y exponerlas de acuerdo a la categoría diseñada según el concepto de Derecho sostenido previamente.

Las resoluciones se pueden clasificar en absolutorias o condenatorias. Estas últimas, a su vez, de acuerdo a las razones por las cuales absuelven: apelación a valores, apelación al Derecho natural como definitorio de lo que es jurídico, argumentos de interpretación "interna" o sistemática propias de la dogmática jurídica o combinaciones. En este sentido, vale lo que decía el profesor Bobbio con respecto a las formas de interpretaraplicar el Derecho.

También aquí encontraremos respuestas inclasificables por no apelar a argumentos sino por su referencia a opiniones personales ${ }^{21}$ o simplemente por carencia de exposición de razones.

Empecemos por las resoluciones de los estudiantes del grupo P: de las 12 respuestas que corresponden a este grupo, solo 1 es absolutoria y corresponde a una argumentación coherente con el positivismo ideológico:

Supongo que lo absolvería ya que no violó la normativa vigente y si lo condenara por una acción que no era considerada delito al momento de su ejecución estaría creando un estado de inseguridad jurídica.

21 Un claro ejemplo es la respuesta de este estudiante: Por mi forma de pensar bajo ningún punto de vista estoy a favor de la pena de muerte. Pena de vida sí, condena lo que corresponda, no más muertes por favor. Esta respuesta pertenece al grupo $\mathrm{P}$ que venimos analizando. 
Entre las resoluciones condenatorias, 2 respuestas emplean una argumentación interna, es decir, que apelan a recursos sistemáticos:

Lo condenaría por Homicidio, o por genocidio tornando más grave la figura, porque en tal caso se debe considerar al Derecho de Gente, el precio de la vida humana, solo un gobierno despótico puede aplicar la analogía y matar gente por medio de una ley. Tal ley es inconstitucional, por tratarse de un gobierno constitucionalmente elegido.

Fallaría en contra de la defensa del abogado porque si bien la CN regula el estado de sitio en caso de emergencia, el presidente no está facultado para cometer actos que excedan esos limites (homicidio) ya que se violarian principios constitucionales y pactos constitucionales con tal jerarquia y también la división de poderes, tomando facultades excesivas y convirtiéndose en un autoritarismo sin respetar la delegación de facultades que también lo marca la Constitución en cuanto a esa división de poderes.

A valores superiores al cumplimiento de la ley refieren 3 respuestas. Nótese que en la primera parte de la respuesta encontramos la expresión de perplejidad que les causa la presencia del positivismo ideológico. Pareciera que estos estudiantes se encuentran incómodos frente a la posibilidad de dejar de lado el derecho positivo, como si esto fuera incompatible con su definición previa:

Si bien la no condena es a todas luces repugnante a la idea de una convivencia social armoniosa, no debe desconocérsele la facultad de cada pais de legislar según sus propios valores, que pueden no ser compartidos por el resto de la comunidad internacional. Una mirada positivista sobre el asunto llevaría a la solución absolutoria, pero pese a la postura que tomé en la pregunta 1, no es lo aconsejable puesto que hace bien a toda sociedad el reconocer el derecho a la vida como un derecho supremo que no podría dejarse de lado por autoridades politicas. Legalmente correspondería absolver, pero sin dudas, axiológicamente para mi escala valorativa correspondería condenar.

Fallaria condenando al ex presidente. Si bien las razones alegadas por el abogado defensor tienen sustento desde el punto de vista jurídico, ya que la declaración del estado de sitio lo facultaba para la imposición de la pena de muerte. Desde el punto de vista de los derechos del hombre "es el derecho a la vida" el más importante, desde mi opinión se estaría violando el derecho de estos ciudadanos.

Tan solo una respuesta sería compatible con las dos tesis que componen la postura iusnaturalista: 
Lo condenaría, ya que si bien su conducta se desempeñó dentro del marco legal, existen normas superiores, naturales y anteriores a la norma positiva. Dichas normas son la consagración de valores inherentes a la humanidad, por ende su violación por más que esté amparada por la Constitución Nacional, es disolvente. "Cuando el derecho se olvida de la realidad, la realidad se olvida del Derecho".

Por último, hay una respuesta que combina la apelación a valores superiores al cumplimiento de la norma positiva y construcciones dogmáticas y 2 inclasificables.

En el grupo $\mathrm{H}$ encontramos todas respuestas condenatorias, de las cuales una combina argumentos, 3 son apelaciones a argumentos sistemáticos y 2 a valores -sin ser por ello jusnaturalistas-. No hay argumentos de tipo "externos", que son los que permitirían no aludir a valores superiores al cumplimiento de la ley sino decidir por la condena ya que el acto del imputado atentó contra el fin del Derecho como instrumento social tal como ellos mismos lo definieron.

En el caso del grupo C, hay 2 respuestas condenatorias. Una con argumentos mixtos, y la otra con argumentos valorativos.

En el grupo TD, la respuesta absolutoria acepta la argumentación del abogado. Y la otra es fiel a su concepto de Derecho, no lo limita al Derecho positivo sino que incorpora las costumbres que le permiten condenar al imputado.

Entre las respuestas trialistas las condenas lo son por motivos combinados entre valores y recursos internos del Derecho, lo mismo que en el grupo D y una de las respuestas del grupo I. La otra respuesta de este grupo es también inclasificable.

En todos los casos se nota la presencia del positivismo ideológico y de la ciencia dogmática. La incomodidad, la perplejidad y la apelación a argumentos mixtos demuestran que el positivismo no puede entenderse como una forma de describir el Derecho sino, más bien, como una forma de teoría de filosofía ética o teoría de la justicia. En este sentido, adherimos a lo que señala Nino, se puede definir el Derecho descriptivamente $y$, congruentemente, optar por dejar de lado su aplicación cuando esta causa una injusticia grave. El cumplimiento de las normas, en última instancia, es producto de una decisión moral. Esta decisión moral de cumplir con las normas jurídicas puede ser dejada de lado cuando sus consecuencias son merituadas como negativas, lo que también es una decisión moral. Esto no afecta en nada el concepto descriptivo del Derecho. 


\section{ANÁlISIS DE LOS DATOS: LA ORIENTACIÓN HACIA LOS SIGNIFI- CADOS RELEVANTES; SIMILITUDES Y DISCORDANCIAS APARENTES EN EL CONCEPTO DE DERECHO. ClASIFICACIÓN FUERTE}

Hemos expuesto que entre los estudiantes de primer ańo y los de los últimos había diferencias a la hora de dar una definición del Derecho. En el primer grupo encontramos mayor simplicidad y una fuerte tendencia a considerar al Derecho como lo hace el positivismo, es decir, de forma unidimensional, estimando al mismo como sinónimo de leyes positivas. Se ve claramente la presencia del positivismo formal o teórico. Dada la característica del caso, y la escasez de tiempo transcurrido en la agencia educativa, no creímos conveniente abordar preguntas de mayor profundidad. Sin embargo, es evidente que hay una influencia menor del discurso pedagógico que sostuvimos como predominante: aquí encontramos un grupo de respuestas que son de clara naturaleza iusnaturalista. Esto no se condice con el mensaje educativo predominante en la Facultad de Derecho. Es decir, el currículum positivista y el código de colección. Para muchos solo se trata de perfeccionar lo que ya sabían, no hay una marcada diferencia entre lo sabido y lo aprendido.

En las definiciones de los estudiantes que cursan Filosofia del Derecho podemos encontrar definiciones más complejas, pero las respuestas positivistas siguen siendo las más numerosas. Si bien entre las respuestas del Ciclo Superior no aparece el concepto de un orden superior o concomitante al positivo, esto surge de las resoluciones condenatorias del caso, con todas las dificultades que encuentran para resolver el caso. Sin embargo, esto no convierte a sus posturas en iusnaturalistas. Es decir, salvo dos estudiantes, nadie dice que el Derecho del Estado imaginario no lo es porque es injusto o no se adecua con los valores superiores a los que adscriben.

Tal como seńalara Nino, no es incompatible sostener un concepto descriptivo de Derecho (positivismo conceptual) y descartar su aplicación en determinadas situaciones. Pero no encuentran simple llegar a esta solución. Y vemos como en muchas respuestas se "divide" lo que consideran jurídico de lo que no lo es: optar por tomar una decisión moral distinta al cumplimiento de la ley en su calidad de supuestos jueces. No consideran jurídico este comportamiento. Y esto no es más que el producto de la caracterización del juez como la bouche de la loi, propia de la exégesis y de la moderna dogmática.

Comparando ambos grupos, resultó inesperado encontrar que en ambos la mayoría de las respuestas son positivistas, en alguna de sus acepciones. Esto habla claramente de una influencia importante del código que permite la orientación hacia significados relevantes propios de la carrera aún en estudiantes con un escaso período de socialización. En cuanto a la desaparición de respuestas jusnaturalistas en los estudiantes del Ciclo 
Superior, esto era esperable. También de esta manera confirmamos, provisoriamente por supuesto, la fuerte presencia del discurso pedagógico descripto.

Por último, si afirmamos que estamos frente a un código de colección, vimos cumplirse varios de sus requisitos a nivel subjetivo. Por ejemplo, los estudiantes diferencian claramente el saber jurídico de los de otro tipo -con las salvedades hechas con respecto a primer ańo-, tienen incorporadas las reglas de jerarquía y respetan a quien tenga el estatus de docente, aun cuando no sea el suyo.

Todo esto nos permite afirmar, provisionalmente, que los estudiantes de primer año han captado el código al menos en su dimensión de la fuerte clasificación (código de colección) de la que goza el Derecho como objeto y como disciplina ${ }^{22}$. Y que los del grupo del Ciclo Superior no solo adquirieron la regla de reconocimiento -que permite comportarse de la manera adecuada - sino también la de realización, como en seguida veremos.

\section{Las prácticas de interacción especializadas y la pedagogía. El en- marcamiento fuerte. Diferencias entre ambos grupos}

En cuanto al enmarcamiento, la forma de control, que a nivel interaccional se da en prácticas especializadas, en el manejo de la reglas de realización, también vemos diferencias. Los estudiantes de primer año no utilizaron los conceptos del trialismo -que se enseña en las comisiones relevadas-, no tuvieron problemas en contestar las preguntas en grupo o consultándose abiertamente. Es decir, el enmarcamiento débil bajo el cual se desarrolló la tarea no fue retraducido por ellos en uno fuerte.

Los estudiantes más avanzados, por el contrario, tomaron la consigna con un principio de enmarcamiento fuerte, a pesar de que se aclaró que se podía responder como se quisiera, respondiendo de manera individual y bajo el más estricto silencio. Aquí hubo aplicación de enmarcamiento fuerte, una decisión que tomaron ellos a pesar de no haber sido lo propuesto. Dos estudiantes hicieron referencia a un concepto cercano a la teoría trialista, lo que puede significar que consideraron que era una instancia evaluativa, de clasificación interna fuerte. A pesar de que durante la actividad hubo quienes preguntaron detalles y manifestaron que faltaban datos para decidir el caso, y que indiqué que podían ponerlo, ninguno puso esto en las respuestas. No se encuentran cómodos criticando al que consideran tiene la autoridad. Manejan, por tanto, las reglas de reconocimiento, como vimos en el apartado anterior, y las de realización propias de la carrera. 


\section{CONCLUSIONES}

Desde ya tenemos que volver a subrayar que esta muestra no es representativa y no puede tomarse de forma definitiva. Pero, al menos, nos permite ir descubriendo un panorama sobre el papel de la estructura social en la conciencia de los ingresantes -que se ha traducido en una producción textual elaborada por un pedido expreso y con una finalidad ajena al desarrollo de la actividad educativa- y el rol del nivel intermedio, la agencia educativa, en la formación de la conciencia jurídica. Sin embargo, dada la sorpresa que nos provocaron las respuestas de los estudiantes de primer ańo, pensamos que este trabajo tiene un valor exploratorio interesante. En cuanto a las respuestas de los estudiantes del Ciclo Superior, se han confirmado las expectativas.

Aunque este trabajo tuvo como una de sus finalidades ser uno de los primeros ingresos al campo, sin dudas sus resultados sirven para abrirnos interrogantes acerca de la fuerza reproductiva de la agencia educativa estudiada, pero también del campo jurídico en términos de Pierre Bourdieu. Esperamos que en el avance en el trabajo empírico aparezcan datos esclarecedores sobre la importancia de la enseńanza del Derecho como hecho formador de la conciencia subjetiva de los estudiantes y, en definitiva, como fuente del Derecho mismo ${ }^{23}$.

\section{BIBLIOGRAFÍA CITADA}

- Bernstein, Basil (1996). Pedagogy, Symbolic Control and Identity. Exeter: Taylor \& Francis.

- Bernstein, Basil (1990). Poder, educación y conciencia. Sociología de la transmisión cultural, trad. Martín Bruggendieck, Cristián Cox, Rosita Puga, Rafael Hernández y Marta Marín. Barcelona: El Roure.

- Brígido, Ana María (2006). Sociología de la educación: temas y perspectivas fundamentales. Córdoba: Ed. Brujas, p. 253.

- Bourdieu, Pierre (2000). Elementos para una sociología del campo jurídico. En Bourdieu, Pierre y Teubner, Gunther. La fuerza del Derecho. Bogotá: Ediciones Uniandes.

- Díaz, Elías (1992). Sociología y Filosofía del Derecho, 1a Ed., reimp. Madrid: Taurus.

- Echeverría, Hugo Darío (2005). Los diseños de investigación y su implementación en Educación. Rosario: Editorial Homo Sapiens.

23 Pérez Lledó, Juan (1992) "La enseñanza del Derecho en Estados Unidos". Revista Doxa, No 12 , pp. 41 y ss. 
- Klimovsky, Gregorio e Hidalgo, Cecilia (2001). La inexplicable sociedad. Cuestiones de epistemología de las ciencias sociales, $3^{\mathrm{a}}$ ed. Buenos Aires: AZ.

- Lista, Carlos y Brígido, Ana María (2002). La enseñanza del Derecho y la formación de la conciencia jurídica. Córdoba: Sima.

- Lista, Carlos y Begala, Silvana (2003) "La presencia del mensaje educativo en la conciencia de los estudiantes: resultados de la socialización en un modelo jurídico dominante". Revista Academia, № 2, Buenos Aires.

- Nino, Carlos (2005). Introducción al análisis del Derecho, 2a Ed. ampliada y revisada, $13^{a}$ reimpresión. Buenos Aires: Astrea.

- Pérez Lledó, Juan (1992) "La enseñanza del Derecho en Estados Unidos". Revista Doxa, № 12.

- Pezzetta, Silvina (2006-2007) "La filosofía y la política en los planes de estudio de las carreras de Abogacía. Reflexiones sobre el Plan de Estudios de la Facultad de Derecho de la U.N.R.". Revista Telemática de Filosofia del Derecho (RTFD) No 10 (1). Disponible en http://dialnet.unirioja.es/servlet/listaarticulos?tipo_ busqueda $=A N U A L I D A D \&$ revista_busqueda $=1951 \&$ clave_busque$\mathrm{da}=2006$ [fecha de visita 20-01-2008]

- Pérez Serrano, Gloria (1998). Investigación cualitativa. Retos e interrogantes. Madrid: La Muralla.

- TAYlor, S.J. y Bodgan, R. (1998). Introducción a los métodos cualitativos de investigación. La buisqueda de los significados. Barcelona: Paidós. 